Valdinei Santos de Aguiar Junior ${ }^{\mathrm{a}}$ (iD) https://orcid.org/0000-0001-7028-8597

Luiz Carlos Fadel de Vasconcellos (iD) https://orcid.org/0000-0002-7679-9870

a Fundação Oswaldo Cruz (Fiocruz), Escola Nacional de Saúde Pública. Rio de Janeiro, RJ, Brasil.

Contato:

Valdinei Santos de Aguiar Junior

E-mail:

vival_rj@hotmail.com

Os autores informam que o trabalho não foi apresentado em eventos científicos e que não foi baseado em dissertação ou tese.

Os autores declaram que o trabalho relatado integrou parte do projeto "Formação continuada de agentes multiplicadores de Vigilância em Saúde do Trabalhador", financiado pelo Ministério da Saúde (Fundo Nacional de Saúde, TED: 122/2017, Processo no 25388.000555-2017-31; Projeto Fiotec - ENSP 024 FIO 18), e que não há conflitos de interesses.

\section{Reflexões sobre a relação trabalho-saúde de crianças e adolescentes: um espaço de intervenção na formação em Saúde do Trabalhador}

\author{
Reflections on the work-health relationship of children and \\ adolescents: an intervention space in worker's health training
}

\section{Resumo}

Introdução: o trabalho infantil é um problema mundial de enormes proporções e com graves consequências sociais. Objetivos: refletir sobre limites e possibilidades do campo da Saúde do Trabalhador (ST) no combate ao trabalho infantil. Métodos: realização de oficina em seminário de formação continuada de multiplicadores de Vigilância em Saúde do Trabalhador (Visat) em 2017, na cidade do Rio de Janeiro, com 25 profissionais de ST de vários estados do Brasil. Resultados: o estudo evidenciou a complexidade do tema e a dificuldade para identificar casos de trabalho infantil, assim como dúvidas quanto a encaminhamentos e procedimentos a serem adotados. Diante disso, constatou-se a necessidade de ampliação da atuação da ST junto às equipes de Atenção Básica em Saúde e de Saúde da Família. Conclusão: intervenções abordando a relação infância/trabalho/saúde nos espaços de formação de profissionais de vigilância, educação e atenção à saúde são potencialmente enriquecedoras. O campo da ST pode trazer à luz aspectos não considerados das situações de trabalho infantil. É, portanto, potencialmente apto a ampliar as possibilidades de atenção à saúde de crianças e adolescentes em situação de trabalho e, consequentemente, contribuir com o combate à exploração do trabalho infantil.

Palavras-chave: trabalho infantil; saúde do trabalhador; saúde pública.

\begin{abstract}
Introduction: child labor is a worldwide problem of enormous proportions and with serious social consequences. Objectives: to reflect about limits and possibilities of the Worker's Health field in the struggle against child labor. Methods: workshop conducted in a training seminar for Worker's Health Surveillance multipliers in 2017, in the city of Rio de Janeiro, with 25 professionals from many states of Brazil. Results: the study showed the theme complexity and the difficulty in identifying child labor cases, as well as doubts regarding referrals and procedures to be adopted. It was also noted the need to improve the performance of the Worker's Health actions together with the teams of Primary Health Care and Family Health. Conclusion: interventions addressing the childhood / work / health relationship during professional training activities in health education, surveillance, and health care are potentially enriching. The field of Worker's Health can elucidate some aspects not considered in child labor situations. Therefore, it is potentially able to expand the possibilities of health care for children and adolescents in work situations and, consequently, contribute to the struggle against the exploitation of child labor.
\end{abstract}

Keywords: child labor; occupational health; public health. 


\section{Introdução}

A exploração do trabalho infantil é um problema mundial de enormes proporções e com graves consequências sociais. A prática é considerada uma forma de violência contra crianças e adolescentes e, por isso, é proibida internacionalmente.

Desde a sua fundação em 1919, a Organização Internacional do Trabalho (OIT) demonstrava que a participação de crianças em alguns setores produtivos deveria ser alvo de legislações e restrições, publicando paulatinamente convenções que estabeleciam idades mínimas para o trabalho em setores produtivos específicos. Mas é somente em 1973, com a Convenção 138, que a OIT estabeleceu que os países signatários adotassem idade mínima para o trabalho em todo e qualquer setor produtivo ${ }^{1}$. Posteriormente, com a Convenção 182 de 1999, prosseguiu determinando o combate ao trabalho infantil no mundo visando erradicá-lo, especialmente o trabalho infantil em suas piores formas ${ }^{2}$.

Na Lista das Piores Formas de Trabalho Infantil (Lista TIP), que classifica e tipifica os trabalhos assim considerados, as justificativas para o combate a estas atividades são os prováveis riscos ocupacionais e os seus prováveis agravos à saúde ${ }^{1}$. Em tese, é evidente que se trata de uma questão na qual as intervenções e produções de conhecimento do campo da Saúde do Trabalhador são cruciais. Contudo, este campo aparenta exercer, na melhor das hipóteses, um papel coadjuvante, com sua potencialidade de intervenção limitada pela complexidade que envolve a questão do combate ao trabalho infantil.

É inegável que o Sistema Único de Saúde (SUS), do qual a Saúde do Trabalhador faz parte, deve contribuir com o combate à exploração do trabalho infantil e com medidas que visem sua erradicação. Deve também oferecer atenção integral à saúde de crianças e adolescentes, estando ou não em situação de trabalho. E, em se encontrando em situação de trabalho, o SUS deveria conseguir analisar, compreender e intervir na relação trabalho/saúde de crianças e adolescentes.

Porém, sendo o trabalho infantil uma atividade ilegal, como trazer à luz a relação trabalho/saúde de crianças e adolescentes que exercem atividades juridicamente proibidas? Como conciliar a paradoxal dupla tarefa do SUS a respeito do trabalho infantil: contribuir com a retirada de crianças e adolescentes da situação de trabalho ilegal; e, simultaneamente, oferecer atenção integral a esses jovens que, por fatores diversos e complexos, podem ter suas atividades de trabalho e os agravos à saúde escamoteados? Considerando a ilegalidade e a invisibilidade do trabalho infantil, como o campo da Saúde do Trabalhador pode intervir?
O presente relato de experiência visa refletir sobre limites e possibilidades desse campo na intervenção ao trabalho infantil, a partir da análise de uma intervenção realizada em curso de formação de multiplicadores de Vigilância em Saúde do Trabalhador (Visat). Reflete sobre as dificuldades relatadas e faz apontamentos no sentido de ampliar a discussão sobre o tema e a intervenção do campo na saúde de crianças e adolescentes trabalhadores.

\section{O trabalho infantil enquanto problema}

Define-se como trabalho infantil toda atividade exercida por pessoa abaixo da idade mínima permitida por lei para aquele ofício ${ }^{3}$. No Brasil, a Constituição Federal de $1988^{4}$, ao especificar o trabalho como um direito social, estabeleceu em seu artigo 7, alínea XXXIII, que o trabalho noturno, perigoso ou insalubre deveria ser proibido aos menores de 18 anos e que aos menores de 14 anos qualquer trabalho seria proibido, exceto na condição de aprendiz. Com a Emenda Constitucional $\mathrm{n}^{\mathrm{o}} 20^{5}$, publicada em 1998, nova redação foi dada a essa alínea, estabelecendo então a "proibição de trabalho noturno, perigoso ou insalubre a menores de dezoito e de qualquer trabalho a menores de dezesseis anos, salvo na condição de aprendiz, a partir de quatorze anos".

Em 2013, na ocasião da III Conferência Global do Trabalho Infantil, o Brasil reafirmou o pacto de acabar com o trabalho infantil ${ }^{3}$. A meta mundial, pactuada nos Objetivos do Desenvolvimento Sustentável, é erradicar do mundo o trabalho infantil em todas as suas formas até $2025^{6}$. Há uma queda no número de crianças trabalhando no mundo. Estima-se que atualmente cerca de 153 milhões de crianças se encontrem em situação de trabalho infantil; entretanto a OIT aponta que, se a tendência de queda dos índices permanecer estável, em 2025 ainda haverá mais de 100 milhões de crianças nessa situação ${ }^{7}$.

Após alguns anos de constante redução nos índices de trabalho infantil no país, o Brasil voltou a apresentar um aumento em 2014, chegando a cerca de 3,3 milhões de crianças entre 5 anos e 17 anos trabalhando no país ${ }^{8}$. Este aumento interrompeu a série histórica de redução do trabalho infantil no Brasil. Contudo em 2016 registrou-se nova queda e estimou-se que 2,6 milhões de jovens entre 5 anos e 17 anos trabalhavam no país ${ }^{9}$. Entretanto, há de se destacar um detalhe: enquanto o número de adolescentes entre 15 anos e 17 anos caiu substancialmente, impactando nos números gerais, houve um aumento de crianças entre 5 anos e 9 anos em situação de trabalho no Brasil ${ }^{9}$.

De qualquer forma, fato é que apesar da redução nos índices de trabalho infantil no país e do intuito 
necessariamente protetivo que embasa a sua proibição e combate, as políticas públicas não são efetivas o suficiente para erradicar essa situação de exploração, nem para atender às demandas de saúde relacionadas ao trabalho. Especialmente neste aspecto, a questão é que, como um possível dano colateral da proibição, pode estar ocorrendo um processo de invisibilização do trabalho infantil ${ }^{10}$. Isto impede que os serviços de saúde identifiquem a relação entre a situação de trabalho e os agravos à saúde de crianças e adolescentes trabalhadores. Ademais, dificulta a compreensão da centralidade do trabalho também na determinação da saúde infanto-juvenil.

Compreende-se que a generalização da definição "trabalho infantil" e, consequentemente, a busca por sua erradicação, têm o objetivo de proteger a infância de forma ampla. Pode-se ainda depreender que esta proteção se ancore em pelo menos dois direitos universais de crianças e adolescentes: o direito à saúde e pleno desenvolvimento e o direito à escolarização. Então, em tese, busca-se a erradicação para proteger a saúde e a educação de milhões de crianças e adolescentes. Entretanto, há de se considerar que os motivos pelos quais se busca a erradicação do trabalho infantil no mundo não se restringem à proteção da infância e da adolescência; assim como considerar que as dificuldades encontradas no enfrentamento e as razões apontadas para o trabalho infantil são, de fato, muito mais complexas do que as campanhas de erradicação demonstram. Assim, a produção de conhecimentos sobre o tema necessita ampliar seu escopo de análise para dar conta da diversidade e complexidade das questões referentes ao trabalho infantil.

Dall'Agnol et al. ${ }^{11}$ apontam que os impactos do trabalho sobre o desenvolvimento psicossocial e intelectual de adolescentes são ainda desconhecidos em países de renda média e/ou baixa, mas constatam prejuízos ao comportamento de adolescentes decorrentes do trabalho infantil. Porém constatam também que os efeitos do trabalho sobre o comportamento têm características diversas de acordo com a idade e o tipo de serviço, e verificam inclusive que "o trabalho dos adolescentes mais velhos, em especial em atividades de serviços não domésticos, pode trazer benefícios ao comportamento" (p. 216).

No Brasil, a produção de conhecimento em saúde sobre o trabalho infantil ainda carece de avanços, seja porque o setor não se apropriou do tema construindo sua própria concepção ${ }^{12}$, seja pela necessidade que se verifica de o "profissional de saúde ter conhecimento dos fatores de risco do ambiente de trabalho, a fim de investigar a possibilidade de exposição ocupacional durante o atendimento de saúde de crianças e adolescentes" (p. 957-8) ${ }^{13}$. Em termos gerais, a centralidade do trabalho na determinação das condições de saúde/doença dos indivíduos e populações ainda é pouco considerada nos serviços de saúde, ficando mais restrita ao campo da Saúde do Trabalhador. À medida que o entendimento, o reconhecimento e a intervenção sobre a relação saúde/ trabalho, sobretudo das crianças, não se ampliam, perdem-se possibilidades tanto de maior cuidado e atenção aos problemas de saúde de crianças e adolescentes, quanto de contribuição no combate à exploração do trabalho infantil.

\section{Metodologia (de intervenção)}

Foi realizada uma intervenção em formato de oficina em um seminário de formação continuada de multiplicadores de Visat em outubro de 2017, na cidade do Rio de Janeiro, com 25 profissionais de vários estados do Brasil. Os multiplicadores são agentes públicos capacitados para ministrar cursos básicos de Visat em todo o país para a implementação da Política Nacional de Saúde do Trabalhador e da Trabalhadora junto à Rede Nacional de Atenção Integral à Saúde do Trabalhador (Renast) ${ }^{14}$. A intervenção teve o objetivo de propiciar o pensamento crítico-reflexivo sobre o tema aos multiplicadores e ampliar as possibilidades de intervenção da Visat em relação ao trabalho de crianças e adolescentes. A oficina foi realizada junto com outras três atividades: dois estudos de caso acompanhados por Centros de Referência em Saúde do Trabalhador (Cerest), que são componentes estruturais da Renast, e um debate sobre câncer ocupacional. Após as quatro atividades os temas foram debatidos de forma transversal, abordando dificuldades na efetivação do direito à saúde no trabalho, na notificação de agravos e, entre outras, na atenção à saúde dos trabalhadores.

A primeira etapa do seminário foi a oficina sobre o trabalho infantil. Esta oficina foi estruturada da seguinte forma: (a) exposição da definição e de dados sobre o trabalho infantil no Brasil e no mundo; (b) apresentação do histórico da proibição e dos principais documentos oficiais sobre o tema; (c) apresentação de questões norteadoras (Por que o trabalho é proibido às crianças? Por que é tão difícil erradicar o trabalho infantil? Quando falamos "trabalho infantil" que "imagem" vem ao seu pensamento? Já teve alguma experiência com algum caso de trabalho infantil? Em sua análise crítica, quais são os problemas existentes? E como a sociedade e o poder público devem encarar o tema?); (d) levantamento de dúvidas e experiências; e (e) reflexão sobre limites e possibilidades de intervenções. Utilizou-se computador com projetor de imagens para apresentação de slides com dados e documentos relacionados ao tema. A apresentação ocorreu em sala com os participantes, dispostos em semicírculo. A dinâmica 
estimulou comentários e opiniões de todos os presentes, valorizando suas experiências e apresentando-lhes fundamentos técnico-jurídicos com o objetivo de gerar reflexão crítica sobre a questão e incentivar futuras estratégias de intervenção.

Algumas falas dos participantes serão utilizadas neste relato para ilustrar a discussão. Por questões éticas visando a garantia do anonimato, a identificação autoral dos depoimentos foi preservada.

\section{Resultados: relatos da oficina}

Verificou-se entre os participantes que, de forma geral, o tema trabalho infantil suscita muitas dúvidas e se apresenta como uma limitação de/em suas práticas. Trata-se de uma questão complexa e que ainda carece de espaços de discussão. Também necessita de perspectivas no campo da saúde que possibilitem o combate mais adequado à exploração do trabalho infantil e uma melhor atenção aos casos de agravos à saúde de crianças e adolescentes notadamente ocasionados pelo trabalho. Destacamos durante a oficina o entendimento de que o combate à exploração do trabalho infantil é uma necessidade e uma urgência, visto os agravos à saúde e à vida de milhões de crianças ao redor do mundo. Contudo pontuamos, de forma a propiciar a reflexão crítica, que este combate ainda carece de maiores esforços e, em nossa análise, de uma perspectiva que considere sua complexidade e os diversos fatores envolvidos em sua ocorrência e continuidade.

Iniciou-se a oficina apresentando a seguinte definição de uma cartilha do Ministério Público ${ }^{15}$ :

O termo trabalho infantil, em sua acepção atual, compreende a realização, por crianças e adolescentes com idade inferior a 16 anos, de atividades que visem à obtenção de ganho para prover o sustento próprio e/ou da família, como também de quaisquer serviços que não tenham remuneração. (p. 9)

Destacou-se também as três exceções possíveis: a aprendizagem, o trabalho artístico e o trabalho desportivo. Em todas as exceções existem regras pré-definidas e providências jurídicas a serem adotadas para que o trabalho de crianças e adolescentes não seja ilegal ${ }^{15}$. Já nesse momento alguns participantes perguntaram o porquê de estas atividades serem exceção. Perguntou-se por que a inserção de crianças nestas atividades é, inclusive, socialmente valorizada. Um dos participantes pontuou ainda que, quanto ao trabalho desportivo, "existem grandes diferenças de investimento. A ginástica olímpica e outras modalidades esportivas não têm o mesmo investimento financeiro e o prestígio que tem o futebol, por exemplo".
A questão da proibição do trabalho infantil e das exceções permitidas por lei disparou curiosidades e reflexões sobre o processo social de construção simbólica da categoria trabalho infantil. Uma participante comentou que "muitas vezes, o menino chega na unidade de atendimento ainda uniformizado [esporte], com uma fratura ou lesão, e, mesmo assim, os profissionais de saúde não têm a perspectiva de correlacionar o agravo ao trabalho”.

Os participantes destacaram que o trabalho infantil é mais associado àquelas situações extenuantes, de trabalho manual, por exemplo, na agricultura. De forma geral, reconhece-se que a questão da correlação entre trabalho e condições de saúde/doença ainda tem uma perspectiva incipiente entre os profissionais de saúde mesmo quando se refere à saúde da população adulta ${ }^{16}$. Entretanto, no caso de crianças e adolescentes, tal correlação pode estar sendo duplamente desconsiderada: devido ao trabalho não ser efetivamente considerado um fator central na determinação das condições de saúde das populações e indivíduos ${ }^{16}$; e por uma relativa invisibilidade do trabalho de crianças e adolescentes ${ }^{10}$.

Ainda questionando sobre as exceções, um participante pontuou a influência que a valorização social e a vontade dos pais têm sobre a inserção de crianças e adolescentes nos trabalhos artísticos e desportivos. Desta forma, nas reflexões iniciais levantadas pelo grupo de participantes, também a questão da causalidade da inserção de crianças no trabalho começou a ser verificada como bem mais complexa do que a impressão vigente, de que as necessidades econômicas eram as únicas causadoras do trabalho infantil. Esse participante colocou que, devido ao prestígio, "muitos pais desejam que seus filhos sejam atores ou jogadores de futebol, influenciando que aquela criança se inicie muito cedo em uma destas atividades. Pode ser que, no fundo, aquela criança nem quisesse isso".

Destaca-se que, no caso das exceções em que a criança pode trabalhar, as medidas necessárias devem proteger a saúde e o direito à escolarização, não podendo, obviamente, haver alguma forma de exploração. Entretanto, ao exemplificarmos com o caso da participação de crianças na ginástica olímpica, pontuou-se que mesmo nas situações de trabalho juridicamente permitidas, ainda é necessário que se amplie a compreensão da relação entre as atividades desempenhadas por crianças e sua saúde. Ponderando se seria possível as atividades desportivas ou artísticas prescindirem do trabalho de crianças e adolescentes, um dos participantes, argumentou que "tem que se levar em consideração a questão de um legado social que envolve a atividade que a criança está desenvolvendo. No caso da ginástica [olímpica], há um outro intuito, que não é o da exploração econômica”. 
A presença de participantes diversos, com relatos e reflexões a partir de suas realidades locais, reforçou que a amplitude da definição de trabalho infantil, por um lado facilita e amplia a noção de que crianças e adolescentes precisam de proteção e atenção quanto à sua participação na sociedade; mas por outro pode desconsiderar alguns aspectos socioculturais que envolvem a participação de crianças e adolescentes em determinadas atividades. Uma participante disse que o trabalho infantil "é uma realidade bem presente no Nordeste. Há cidades onde os filhos precisam acompanhar seus pais nos seus trabalhos e acabam ajudando". Outro participante argumentou que: "de fato é uma questão muito complexa. Mas estou aqui pensando, se houver uma maior abertura, uma relativização do termo, não se corre o risco de ter um efeito contrário [no sentido de maior permissividade com o trabalho infantil]?"

Evidentemente, não se pode retroceder ou tergiversar no que tange ao combate à exploração do trabalho de crianças e adolescentes. Entretanto, a questão que se colocou é se a falta de compreensão da complexidade e diversidade de situações e, consequentemente, ausência de perspectiva mais próxima e específica sobre a relação saúde/trabalho de crianças e adolescentes não estariam sendo uma lacuna desconsiderada. Assim, quando se apresentou as estimativas atuais do trabalho infantil no mundo, evidenciando que milhões de crianças e adolescentes ainda trabalham, muitos naquelas consideradas as piores formas de trabalho infantil, sustentou-se o argumento de que a proibição não deve ser um aspecto que adversamente restrinja o direito à saúde de crianças e adolescentes. Em outras palavras, até que o trabalho infantil seja de fato erradicado, a saúde deve buscar e fomentar estratégias de atenção integral aos jovens em situação de trabalho, verificando e intervindo na correlação trabalho-saúde.

Uma das participantes ilustrou a dificuldade das unidades de saúde afirmando que:

É muito difícil identificar e lidar com casos de trabalho infantil. Primeiro, porque os responsáveis não podem informar a situação de trabalho das crianças. Segundo, porque os próprios profissionais de saúde não sabem como lidar com uma situação em que tudo indica que a criança estava trabalhando.

Outra participante relatou que:

Esse momento [da oficina] está sendo muito importante para refletirmos sobre o trabalho infantil. São várias questões que nem pensamos, e é uma realidade tão presente ao redor da gente em muitos estados. A Saúde do Trabalhador deve se envolver mais.

Levantou-se então a questão sobre como o campo da Saúde do Trabalhador e o SUS devem ou podem proceder em relação ao trabalho infantil.
Apresentaram-se alguns documentos da legislação relacionada ao trabalho infantil no Brasil, com destaque para a Portaria $\mathrm{n}^{0} 777$, de 28 de abril de $2004^{17}$, que "Dispõe sobre os procedimentos técnicos para a notificação compulsória de agravos à Saúde do Trabalhador em rede de serviços sentinela específica, no SUS”. Essa portaria especifica os acidentes de trabalho com crianças e adolescentes como agravos de notificação compulsória. Em seguida, apresentamos a cartilha Trabalho infantil: diretrizes para atenção integral à saúde de crianças e adolescentes economicamente ativos $^{18}$, publicada em 2005 pelo Ministério da Saúde na Série "Normas e Manuais Técnicos" de Saúde do Trabalhador. Destaca a determinação aos profissionais de saúde de que "toda criança e adolescente (meninos e meninas até 15 anos) em situação de trabalho deve ser imediatamente retirada da atividade laborativa" (p. 12) ${ }^{18}$. Com base nos documentos legais cabe ao SUS, pelo menos, duas tarefas nesse embate: dar atenção integral à saúde de crianças e adolescentes em situação de trabalho; e contribuir com a erradicação do trabalho infantil.

Deparou-se, durante a oficina, com a necessidade de se pensar em formas de efetivar esta dupla tarefa do SUS. Uma das propostas/reflexões levantadas foi que o campo da Saúde do Trabalhador se aprofunde mais em questões que envolvem o trabalho de crianças e adolescentes. A outra foi a importância dos profissionais das equipes de Saúde da Família (eSF) e das Unidades Básicas de Saúde (UBS) conseguirem identificar e lidar com situações de trabalho infantil. Reforçamos também que a atenção aos direitos das crianças e adolescentes, incluindo o direito à saúde, exigem constante e efetivo diálogo entre diversos setores e instituições para além dos serviços de saúde, dando como exemplo os Conselhos Tutelares. Dentre os profissionais presentes, alguns demonstraram conhecer a necessidade de se notificar e atuar/dialogar com Conselhos Tutelares, Centros de Referência Especializado de Assistência Social (CREAS) e o Ministério Público nos casos de trabalho infantil. Outros confessaram não ter ideia de como articular com outros setores para lidar com a situação.

Um dos participantes, dando a entender que era descrente da efetividade da aplicação dos direitos infantojuvenis em certas regiões do país, questionou: "O que acontece quando pai e mãe trabalham o dia todo, num trabalho pesado, no interior, e não conseguem deixar a criança com ninguém porque não têm condições onde moram"? Como resposta a esta indagação informou-se que seria necessário analisar melhor o caso para que medidas protetivas em favor da criança fossem tomadas, considerando o intuito também de não se penalizar a família. Disse-se ainda que o Ministério Público e os juizados especiais têm, em casos como esse, a atribuição de forçar o poder público 
a garantir contrapartidas necessárias para a retirada da possível situação de trabalho, por exemplo, inserindo-os em creches e escolas. O referido participante, então, falou: "acho muito difícil que a Justiça tenha essa sensibilidade nas realidades das cidades que conheço. Acho mesmo que 'pegaria' é para os pais”.

\section{Reflexões: limites e possibilidades}

Tendo como base os comentários, a participação e a posterior avaliação dos participantes, concluímos que a proposta e a metodologia da intervenção foram adequadas aos objetivos de fomentar o debate e o interesse sobre o tema do trabalho infantil. Construiu-se junto com os multiplicadores de Visat uma perspectiva crítico-reflexiva com aspectos teóricos, técnicos e jurídicos para lidar com o problema da exploração do trabalho infantil. Destaca-se também que a proposta de um curso de formação de multiplicadores de Visat favorece que a discussão sobre o tema, bem como sobre outros pontos relevantes à Saúde do Trabalhador, seja ampliada à medida que os participantes do curso têm como objetivo formar agentes de Visat em todo o país.

Verificou-se que, entre os participantes, o tema do trabalho infantil não parecia ser uma preocupação central ou objeto de intervenção de suas práticas e rotinas de trabalho, embora grande parte tenha relatado que essa é uma realidade presente em seus territórios de atuação. Após a oficina, alguns participantes sinalizaram a necessidade de que o tema seja mais abordado entre os profissionais que atuam na Saúde do Trabalhador. Consideramos que, devido ao seu referencial técnico, teórico e ético, esse campo é potencialmente apto a ampliar as possibilidades de atenção à saúde de crianças e adolescentes em situação de trabalho e, consequentemente, contribuir com o combate à essa prática. À medida que questiona e põe em análise não somente a dimensão técnica do trabalho, mas também sua dimensão social ${ }^{16,19}$, a Saúde do Trabalhador pode trazer à luz aspectos muitas vezes desconsiderados das diversas situações de trabalho de crianças e adolescentes, fomentando uma atuação mais próxima, efetiva e integral no que tange à atenção à saúde dessa população.

Ademais, os participantes compreenderam que a relação entre saúde infantojuvenil e trabalho extrapola a questão do trabalho infantil: de uma forma ainda mais ampla, essa relação tem fundamental importância sobre a saúde dos jovens quando, por exemplo, os acidentes de trabalho com adultos impactam diretamente na vida de seus filhos.

Como bem destacado pelos participantes da oficina, faz-se necessário que a questão da relação saúde/trabalho de crianças e adolescentes seja levada aos profissionais das eSF com vistas a ampliar a capilaridade do SUS sobre o problema da exploração do trabalho infantil. Dadas as características de sua atuação, os profissionais das eSF estão mais próximos dos jovens trabalhadores, com maior potencialidade de intervenção e identificação de casos.

Apesar de seu intuito notadamente protetivo, a proibição e o combate ao trabalho infantil é, ainda, um fator que dificulta a identificação de casos de exploração do trabalho de crianças e adolescentes e a construção de conhecimentos e práticas a respeito da relação infância/trabalho/saúde. A participação e a importância de crianças e adolescentes na estrutura social ainda são pouco consideradas ou reconhecidas, embora, de uma forma ou de outra, eles estejam participando ativamente da construção da realidade social $^{20-24}$. Como pontua Qvortrup ${ }^{21,22}$, devido à falta de reflexão crítica e de reconhecimento da importância da infância e adolescência, condutas em tese protetivas podem excluir os jovens das sociedades modernas capitalistas. Considerando esse paradoxo, sublinhamos que o SUS depara com a difícil e necessária tarefa de contribuir com a erradicação da exploração do trabalho infantil sem, com isso, excluir o direito à atenção integral à saúde de crianças e adolescentes em situação de trabalho.

\section{Considerações finais}

Consideramos que as questões que envolvem o trabalho infantil são de fato complexas devido à diversidade de situações, causas e consequências relacionadas ao trabalho de crianças e adolescentes. É inegável que a proibição e busca pela erradicação do trabalho infantil têm intuito protetivo; contudo, cabe ainda a construção de reflexões críticas e estratégias de intervenção que levem em conta a diversidade cultural, as relações sociais e as necessidades de saúde da população brasileira.

Verificamos que a proposta da intervenção realizada, qual seja, da criação de espaços de debate sobre a relação entre infância, trabalho e saúde, é propícia para fomentar e ampliar a discussão sobre as possibilidades e limites da Saúde do Trabalhador e do SUS em relação ao problema da exploração do trabalho infantil. À medida que se propôs a construção de conhecimento correlacionando as experiências e opiniões dos participantes com a legislação vigente, os dados e aspectos históricos e as diretrizes técnicas relacionados ao trabalho infantil, despertou-se maior interesse dos participantes para o tema e reforçou-se a importância e a necessidade de outros e maiores esforços em prol da atenção à saúde de crianças e adolescentes trabalhadores. 
Observamos que a correlação de conhecimentos sobre a dimensão social da infância e sobre Saúde do Trabalhador pode ampliar, para além do tema do trabalho infantil, a compreensão da centralidade do trabalho nas condições de saúde dos indivíduos e populações. Assim, apontamos que intervenções abordando a relação infância/trabalho/saúde, implementadas em espaços de formação de profissionais de vigilância, educação e atenção à saúde são potencialmente enriquecedoras de práticas e reflexões.

\section{Contribuições de autoria}

Aguiar VS Jr contribuiu com a concepção do trabalho, a análise das informações, a elaboração do manuscrito, a revisão crítica e a aprovação da versão final. Vasconcellos LCF contribuiu com a análise das informações, a elaboração do manuscrito, a revisão crítica e a aprovação da versão final. Os autores assumem integral responsabilidade pelo conteúdo do trabalho publicado.

\section{Referências}

1. Organização Internacional do Trabalho. C138 Idade Mínima para Admissão [Internet]. 1973 [citado em 13 mar 2020]. Disponível em: https://www.ilo.org/brasilia/temas/trabalho-infantil/ WCMS_235872/lang--pt/index.htm

2. Organização Internacional do Trabalho. C182 Convenção Sobre Proibição das Piores Formas de Trabalho Infantil e Ação Imediata para sua Eliminação [Internet]. 1999 [citado em 13 mar 2020]. Disponível em: https://www.ilo.org/brasilia/temas/ trabalho-infantil/WCMS_236696/lang--pt/index.htm

3. Brasil, Organização Internacional do Trabalho. III Conferência Global Sobre Trabalho Infantil [Internet]. 2013 [citado em 13 mar 2020]. Disponível em: https:/www.ilo.org/brasilia/ publicacoes/WCMS_398475/lang--pt/index.htm

4. Brasil. Constituição da República Federativa do Brasil de 1988. Diário Oficial da União [Internet]. 5 out 1988 [citado em 13 mar 2020]. Disponível em: http://www.planalto.gov.br/ccivil_03/constituicao/ constituicao.htm

5. Brasil. Emenda Constitucional $\mathrm{n}^{0} 20$, de 15 de dezembro de 1998. Modifica o sistema de previdência social, estabelece normas de transição e dá outras providências. Diário Oficial da União [Internet]. 15 dez 1998 [citado em 13 mar 2020]. Disponível em: www.planalto.gov.br/ccivil_03/ constituicao/emendas/emc/emc20.htm

6. Organização das Nações Unidas. Transformando nosso mundo: a Agenda 2030 para o Desenvolvimento Sustentável [Internet]. 2015 [citado em 13 mar 2020]. Disponível em: https://nacoesunidas.org/wp-content/ uploads/2015/10/agenda2030-pt-br.pdf

7. International Labour Office. Global estimates of child labour: results and trends, 2012-2016 [Internet]. 2017 [citado em 13 mar 2020]. Available from: https://www.ilo.org/wcmsp5/groups/public/--dgreports/---dcomm/documents/publication/ wcms_575499.pdf

8. Fórum Nacional de Prevenção e Erradicação do Trabalho Infantil. O trabalho infantil nos principais grupamentos de atividades econômica do Brasil
[Internet]. 2016 [citado em 01 abr 2020]. Disponível em: https://fnpeti.org.br/media/12dejunho/ documentos-de-referencia/O_Trabalho_Infantil_ nos_Principais_Grupamentos_de_Ati.pdf

9. Observatório da Criança e do Adolescente. População entre 5 e 17 anos ocupada [Internet]. 2015 [citado em 13 mar 2020]. Disponível em: https://observatoriocrianca.org.br/cenario-infancia/ temas/trabalho-infantil/621-populacao-entre-5-e17-anos-ocupada?filters $=1,236$

10. Aguiar Junior VS, Vasconcellos LCF. Infância, trabalho e saúde: reflexões sobre o discurso oficial de proibição do trabalho infantil. Saúde Debate. Jun. 2017;41(Spec No):25-38.

11. Dall'Agnol MM, Fassa AG, Facchini LA, Benvegnú LA. Associação do trabalho infantil com transtornos de comportamento do tipo introversão e extroversão: um estudo transversal no Sul do Brasil. Rev Bras Saúde Ocup. 2015;40(132):206-18.

12. Nobre LCC. Trabalho de crianças e adolescentes: desafios da intersetorialidade e o papel do Sistema Único de Saúde. Ciênc saúde coletiva. 2003;8(4):963-71.

13. Asmus CIRF, Raymundo CM, Barker SL, Pepe CCCA, Ruzany MH. Atenção integral à saúde de adolescentes em situação de trabalho: lições aprendidas. Ciênc saúde coletiva. 2005;10(4):953-60.

14. Vasconcellos LCF, Almeida CVB, Guedes DT. Vigilância em Saúde do Trabalhador: passos para uma pedagogia. Trab educ saúde. 2009;7(3):445-62.

15. Medeiros Neto XT, Marques RD. Manual de atuação do Ministério Público na prevenção e erradicação do trabalho infantil. Brasília: CNMP; 2013.

16. Vasconcellos LCF, Machado JMH. Política Nacional de Saúde do Trabalhador: ampliação do objeto em direção a uma política de Estado. In: MinayoGomez C, Machado JMH, Pena PGL, organizadores. Saúde do trabalhador na sociedade brasileira contemporânea. Rio de Janeiro: Editora Fiocruz; 2011. p. 37-65.

17. Brasil. Portaria no 777/GM, de 28 de abril de 2004. Dispõe sobre os procedimentos técnicos para 
a notificação compulsória de agravos à saúde do trabalhador em rede de serviços sentinela específica, no Sistema Único de Saúde - SUS. Brasília: Ministério da Saúde; 2004.

18. Brasil. Ministério da Saúde. Trabalho infantil: diretrizes para atenção integral à saúde de crianças e adolescentes economicamente ativos. Brasília: Editora do Ministério da Saúde; 2005.

19. Minayo-Gomez C. Campo da Saúde do Trabalhador: trajetória, configuração e transformações. In: Minayo-Gomez C, Machado JMH, Pena PGL, organizadores. Saúde do trabalhador na sociedade brasileira contemporânea. Rio de Janeiro: Editora Fiocruz; 2011. p. 23-33.
20. Qvortrup J. Nove teses sobre a "infância como um fenômeno social”. Pro-Posiçoes. 2011;22(1):199-211.

21. Qvortrup J. A infância enquanto categoria estrutural. Educ Pesq. 2010;36(2):631-43.

22. Qvortrup J. Visibilidades das crianças e da infância. Linhas Críticas. 2014;20(41): 23-42.

23. Aguiar Junior VS, Vasconcellos LCF. A importância histórica e social da infância para a construção do direito à saúde no trabalho. Saude Soc. 2017;26(1):271-85.

24. Corsaro WA. Sociologia da infância. Porto Alegre: Artmed; 2011. 